\title{
STUDY ON CONVENTIONAL RISK FACTORS IN ACUTE CORONARY SYNDROME
}

\author{
Prabin Khatri ${ }^{1}$, Rabindra Simkhada ${ }^{2}$
}

\begin{abstract}
INTRODUCTION: Acute coronary syndrome is one of the common cardiovascular diseases. Smoking, dyslipidemia, hypertension, diabetes and obesity are conventional risk factors. Different studies have shown variable prevalence of these risk factors. This study was designed to see the prevalence of these risk factors in our setting and see their correlation with different types of acute coronary syndrome.
\end{abstract}

MATERIAL AND METHOD: This was a hospital based observational study conducted at Universal College of Medical Science Teaching Hospital, Bhairahawa from September 2012 to August 2013. A total of 100 consecutive patients were enrolled after applying inclusion and exclusion criteria.

RESULTS: Out of 100 study patients, $64 \%$ were male and $36 \%$ were female. Their age ranged from 30 years to 87 years with mean age of $60 \pm 12.90$ year. Hypertension was present in $64 \%, 62 \%$ were dyslipidemic. Similarly $39 \%$ were smoker and $19 \%$ had diabetes. Sex $(p=0.01)$ and hypertension $(p<.01)$ showed significant positive correlation with type of acute coronary syndrome.

CONCLUSION: Hypertension was the most prevalent risk factor for the occurrence of acute coronary syndrome. Diabetes mellitus, smoking, and dyslipidemia was also present in considerable numbers. Gender and hypertension showed significant positive correlation with type of Acute Coronary Syndrome.

KEYWORDS: Acute coronary syndrome; Hypertension; Risk factors

1. Assistant Professor, Department of Cardiology, Universal College of Medical Sciences \& Teaching Hospital, Bhairawa, Nepal

2. Associate Professor, Department of Cardiology, Universal College of Medical Sciences \& Teaching Hospital, Bhairawa, Nepal

\author{
For Correspondence \\ Dr. Prabin Khatri \\ Assistant professor, \\ Department of Cardiology, \\ Universal College of Medical Sciences \& Teaching Hospital, \\ Bhairawa, Nepal \\ E-mail:prabinkhatri@hotmail.com
}




\section{INTRODUCTION}

Cardiovascular disease (CVD) has emerged as a major health burden worldwide. This contributed to 15.3 million deaths in 1996, of which 5.5 million were from developed countries and 9.77 million from developing countries. ${ }^{1}$ A rise in the prevalence of CVD in the early half of twentieth century and a subsequent decline in the latter half have been well documented in the industrialized countries. However, the scenario is reversed in developing countries with a steady escalation in prevalence of CVD. ${ }^{2}$

There is paucity of data on acute coronary syndrome in Nepal. Definite diagnosis of myocardial infarction was made in Nepal in 1945 and from the sixties the incidence started rising rapidly. In a study between 1960-1968 a total of 150 cases of myocardial infarction (MI) were reported in Kathmandu, Nepal. Among them $89.9 \%$ were smokers, $28 \%$ hypertensive, $14.3 \%$ diabetics and $25.4 \%$ were with hypercholesterolemia. In 1990, the admission pattern of Teaching Hospital, Kathmandu showed respiratory diseases to be $1^{\text {st }}$ disease followed by gastrointestinal and cardiovascular diseases. However, in 2000 cardiovascular diseases constituted $20 \%$ of medical admission out of which $8 \%$ were coronary artery disease (CAD). The ten years data of teaching hospital among CAD patients showed $74 \%$ male and $26 \%$ female. Among them $82 \%$ were smokers, $40 \%$ hypertensive, $22 \%$ diabetic, $20 \%$ showed raised LDL and $10 \%$ showed raised triglyceride. Among the cases of hospital admissions in National Heart Centre between 2001-2002, coronary artery disease was the commonest cause $(26.5 \%)$ followed by rheumatic heart disease $(25.97 \%)$. Data shows there have been significant increase in incidence of MI in last several decades. Prevalence of coronary artery disease (CAD) estimated from the figures of acute MI cases indicate that $5 \%$ of adult population in Kathmandu suffer from CAD and the disease has reached epidemic proportion in Kathmandu. ${ }^{3}$

Acute Coronary Syndrome is one of the important emerging health concerns of Nepal. The study was carried out to see the prevalence of conventional risk factors among the patients of acute coronary syndrome in our settings.

\section{MATERIAL AND METHODS}

This was an observational study conducted at Department of Internal Medicine, Universal College of Medical Sciences (UCMS), Bhairahawa during September 2012 to August 2013. The study was approved by the institutional review board and informed consent was obtained from all the participants. Patients presenting with clinical features of acute coronary syndrome were followed. Patients with the evidence of acute coronary syndrome (Unstable angina, Non ST elevation MI, ST elevation MI) according to WHO criteria were included in the study. Patients unwilling to give consent for the study, and with valvular heart diseases and congenital abnormalities of heart were excluded.

Hypertension was defined according to JNC 7 guideline. Diabetes was considered if the patient was previously diagnosed as diabetic, on diabetic medications or if found to have fasting glucose $\geq 7 \mathrm{mmol} / \mathrm{L}(126 \mathrm{mg} / \mathrm{dl})$ or 2 hours post prandial glucose $\geq 11.1 \mathrm{mmol} / \mathrm{L}(200 \mathrm{mg} / \mathrm{dl})$ or random blood sugar $\geq 11.1 \mathrm{mmol} / \mathrm{L}(200 \mathrm{mg} / \mathrm{dl})$ as per the ADA 2011 diagnostic criteria. Blood samples were taken for estimation of lipid profile within 24 hours of acute coronary syndrome. Statistical analysis was done using SPSS version 16.0 for Windows. Categorical data was expressed as frequencies and corresponding percentages. Parametric data were expressed in mean \pm SD. Categorical data were evaluated by 'chi square' test. Level of significance for all analytical test were set at 0.05 and ' $\mathrm{p}$ ' value $\leq 0.05$ was considered significant.

\section{RESULT}

Out of 100 patients, $64 \%$ were male and $36 \%$ were female. Their age ranged from 30 years to 87 years with mean age of $60 \pm 12.90$ years. Maximum number of patients (31\%) belonged to age group 50-60 years. Among 100 patient, 44\% had STEMI, 29\% had unstable angina and remaining $27 \%$ of the patients were suffering from NSTEMI which is shown in table 1 .

Table 1: Frequency of types of $\operatorname{ACS}(\mathrm{No}=100)$

\begin{tabular}{|l|l|}
\hline Type of ACS & Frequency \& Percent \\
\hline Acute STEMI & 44 \\
\hline Acute NSTEMI & 27 \\
\hline Unstable angina & 29 \\
\hline
\end{tabular}

A total of $68 \%$ were found to be suffering from hypertension. Among 100 participants $19 \%$ were diabetic. A total of $62 \%$ were found to be dyslipidemic. Thirty-nine percent of the participants were smoker. A total of $64 \%$ of study population were alcohol consumer. Sixty-five percentage participants' body mass index was within 18.5 24.9. Table 2 summarize the frequency of conventional risk factors in ACS. 
Table 2: Conventional risk factors in ACS

\begin{tabular}{|l|l|}
\hline Risk Factors & Frequency \\
\hline Male Sex & $64 \%$ \\
\hline Hypertension & $68 \%$ \\
\hline Diabetes & $19 \%$ \\
\hline Smoking & $39 \%$ \\
\hline Dyslipidemia & $62 \%$ \\
\hline
\end{tabular}

There was statistically significant correlation of the types of ACS with sex $(P=0.01)$. A total of 19 male and 8 female had NSTEMI, 33 male and 11 female had STEMI, where as unstable angina was more prevalent in female. Out of 29 unstable angina 17 were female. Similarly hypertension also showed significant correlation with types of ACS. Out of 44 STEMI 37 were hypertensive, out of 27 NSTEMI 19 were hypertensive, on the other-hand only 12 were hypertensive among 29 unstable angina $(\mathrm{p}<0.01)$ age, diabetes, smoking, dyslipidemia, obesity, consumption of alcohol showed no statistical significant correlation with the type of ACS, which is shown in table 3 .

\section{Table 3: Statistical Significance of different variables}

\begin{tabular}{|l|l|}
\hline Variables & P values \\
\hline Age & 0.45 \\
\hline Sex & 0.01 \\
\hline Hypertension & $<.01$ \\
\hline Diabetes & 0.94 \\
\hline Obesity & 0.51 \\
\hline Dyslipidemia & 0.64 \\
\hline Smoking & 0.27 \\
\hline Alcohol consumption & 0.88 \\
\hline
\end{tabular}

\section{DISCUSSION}

There are several well established conventional risk factors of acute coronary syndrome like age, sex, hypertension, diabetes mellitus, dyslipidemia, smoking, and obesity. In this study we found $68 \%$ hypertensive and $19 \%$ diabetic. A total of the $62 \%$ were found to be dyslipidemic. Thirty-nine percent of the participants were smoker. A total of $64 \%$ of study population were alcohol consumer.

Butt $\mathrm{Z}$ and colleagues have found $91 \%$ of subjects of acute coronary syndrome had at least one risk factor. ${ }^{4}$ It has also been documented that when the risk factors coexist, it multiples the risk several folds. ${ }^{5}$ Similarly in a study by Selim S and colleague, from Bangladesh, smoking tobacco, diabetes mellitus, hypertension, visceral obesity and less fruit intake were the important factors of acute coronary syndrome in Bangladesh. ${ }^{6}$ Seventy percent of cases and $45 \%$ of controls smoked cigarettes. Effect of smoking in cardiovascular disease and benefit of quitting consumption have been well documented in literatures. ${ }^{7,89}$ Consumption of non smoke tobacco is also the risk factor.

In a study conducted by Gururajan P, levels of total cholesterol and LDL-cholesterol were significantly raised in patients when compared to controls and lower level of HDLcholesterol was also observed in them. Vitamin C, vitamin E, reduced glutathione, MDA and protein thiol levels were also significantly lowered in patients than controls $(\mathrm{p}<0.05) .{ }^{10}$

Baber $U$ and colleagues reported diabetes mellitus one of the common risk factor among patients presenting with acute coronary syndromes. Despite significant reductions in cardiovascular morbidity and mortality over the last half century, residual vascular risk remains disproportionately high in these populations. ${ }^{11}$ Several other studies have evaluated the risk of cardiovascular disease among diabetics. ${ }^{12,13,14}$

There was no statistically significant association found between the type of acute coronary syndrome in different age groups $(\mathrm{P}=0.452)$. Significant association was found between the acute coronary syndrome and sex. This was in accordance with the study conducted among South Asian Indian population from South Africa by Ranjith N. ${ }^{15}$ This study found significant positive correlation of gender with type of acute coronary syndrome. Unstable angina was more common in female. This is in accordance with the published literatures.

\section{CONCLUSION}

The prevalence of conventional risk factors of acute coronary syndrome was analyzed in this study. Hypertension was present in $64 \%$. Thirty nine percent were smoker and $19 \%$ had diabetes. Those patients who have those conventional risk factors thus are at increased risk of ACS and a vigilant suspicion should be considered. On the other hand timely and appropriate measures should be taken to modify and control those risk factors to decrease the incidence of acute coronary syndrome. 


\section{REFERENCES}

1. Murray CL, Lopez AD. Alternative projection of mortality and morbidity by cause 1990-2020; Global Burden of disease study. Lancet 1997; 349: 1498-1504. http://dx.doi.org/10.1016/S01406736(96)07492-2

2. Reddy KS, Yusuf S. Emerging epidemic of cardiovascular disease in developing countries. Circulation 1998; 97: 596-601. http://dx.doi.org/10.1161/01.CIR.97.6.596

3. Maskey A, Sayami A, Pandey MR. Coronary artery disease : Anemerging epidemic in Nepal. JNMA; 2003: 42.

4. Butt Z, Shahbaz U, Hashmi A.T, et.al. Frequency of Conventional Risk Factors in Patients with Acute Coronary Syndrome in Males and Females, Pathology Department, King Edward Medical University, Lahore. ANNALS 2010; 16: 55-58.

5. Paul MR, Libby P. Risk factors for atherosclerotic disease. In: Braunwald E, .Libby P, Zipes DP, et al. Heart disease. 6th Ed. Phaliadelphia PA: Elsevier Health sciences; 2001. p. 1010-39.

6. Selim S, Rahman R, Yasmin R, et al. Risk Factors of Acute Coronary Syndrome among Bangladeshi People, Department of Endocrinology \& Metabolism, BIRDEM, Dhaka, Bangladesh: Mymensingh MedJ 2013; 22(3): 513-21.

PMid:23982542

7. Ezzati M, Henley SJ, Thun MJ, et al. Role of smoking in global and regional cardiovascular mortality. Circulation 2005; 112: 489. http://dx.doi.org/10.1161/CIRCULATIONAHA.104.521708 PMid:16027251

8. Kurth T, Kase CS, Berger $K$, et al. Smoking and the risk of hemorrhagic stroke in men. Stroke 2003; 34: 1151. http://dx.doi.org/10.1161/01.STR.0000065200.93070.32 http://dx.doi.org/10.1161/01.STR.0000100165.36466.95
9. Critchley JA, Capewell S. Mortality risk reduction associated with smoking cessation in patients with coronary heart disease : a systematic review. JAMA 2003; 290: 86. http://dx.doi.org/10.1001/jama.290.1.86 PMid:12837716

10. Gururajan P, Gurumurthy P, Nayar P, et al. Lipid profile and nonenzymic antioxidant status in patients with acute coronary syndrome in South India, Department of Biochemistry. International Centre for Cardiothoracic and Vascular Diseases, R-30 C Ambattur Industrial Estate Road, Mogappair, Chennai 600101, India. Heart Lung Circ 2010; 19(2): 75-80. http://dx.doi.org/10.1016/j.hlc.2009.07.003 PMid:19914867

11.Baber $U$, Auguste U. Patients with chronic kidney disease/diabetes mellitus: the high-risk profile in acute coronary syndrome. Usman. Curr Cardiol Rep 2013; 15(8): 386. http://dx.doi.org/10.1007/s11886-013-0386-y PMid:23843182

12. Antin MA, Hokanson JE, Edwards KL. Hyperglyceridemia as a cardiovascular risk factor; American J. of Card 1998; 81(4A): $7 B-12 B$.

13.Beckman JA, Creager MA, Libby P. Diabetes and atherosclerosis: epidemiology, pathophysiology, and management. JAMA 2002; 287: 2570 .

http://dx.doi.org/10.1001/jama.287.19.2570 PMid:12020339

14. Kannel. WB, D'Agostino RB, Wilson PW, et al. Diabetes fibrogen and risk of cardiovascular disease- the Framingham experience; American Heart Journal, 1990; 120: 672-76. http://dx.doi.org/ 10.1016/0002-8703(90)90026-T

15. Ranjith N, Pegoraro RJ, Zaahl MG. Risk Factors Associated with Acute Coronary Syndromes in South African Asian Indian Patients [The AIR Study]. J Clinic Experiment Cardiol 2011; 2: 163. http://dx.doi.org/10.4172/2155-9880.1000163 